This is a post-peer-review, pre-copyedit version of an article published in Neuropraxis. The final authenticated version is available online at: https://doi.org/10.1007/s12474-019-00232-4 


\section{De ontwikkeling van het sociale brein: meer begrip van sociale en antisociale trajecten}

Eduard T. Klapwijk, Eveline A. Crone

Instituut Psychologie, Ontwikkelings- en Onderwijspsychologie, Universiteit Leiden

Leiden Institute for Brain and Cognition

\section{Corresponderend auteur:}

Eduard T. Klapwijk

Instituut Psychologie, Ontwikkelings- en onderwijspsychologie, Universiteit Leiden

Wassenaarseweg 522333 AK Leiden

e.t.klapwijk@fsw.leidenuniv.nl

Keywords: hersenontwikkeling, sociale brein, antisociaal gedrag, perspectief-nemen, empathie

Aantal woorden (excl. samenvatting en bibliografie): 2341

Funding: This project has received funding from the European Research Council (ERC) under the European Union's Horizon 2020 research and innovation programme (grant agreement No. 681632).

This is a post-peer-review, pre-copyedit version of an article published in Neuropraxis. The final authenticated version is available online at https://doi.org/10.1007/s12474-019-00232-4 


\section{Samenvatting}

Sociale vaardigheden zijn cruciaal voor een goede ontwikkeling van kind tot volwassene. In dit artikel bespreken we de ontwikkeling het sociale brein, opgedeeld in verschillende hersennetwerken die betrokken zijn bij verschillende sociale vaardigheden. We richten ons met name op de adolescentie, een vormende periode waarin jongeren zich kunnen ontwikkelen tot sociaal-betrokken volwassenen. Ook bespreken we wat bekend is over het functioneren van deze hersennetwerken bij jongeren die antisociaal gedrag vertonen, een groep die deels gekenmerkt wordt door afwijkend sociaal functioneren en het benadelen van anderen. De hersengebieden betrokken bij acceptatie en afwijzing en het ervaren van empathie zijn gevoelig voor onderlinge verschillen en omgevingsinvloeden, en lijken grotendeels uitgerijpt voor de adolescentie. Het hersennetwerk voor perspectief-nemen ontwikkelt zich structureel en functioneel nog door gedurende de adolescentie. Ook wijken deze netwerken op verschillende manieren af bij jongeren die antisociaal gedrag vertonen; met name op het gebied van empathie en perspectief nemen.

\section{Introductie}

Een van de meest onderscheidende vaardigheden van mensen, in vergelijking met andere dieren, is het kunnen uitvoeren van complexe en flexibele sociale interacties met soortgenoten. Deze gerichtheid op soortgenoten is al zichtbaar vanaf onze geboorte. Zo vertonen pasgeboren baby's al een sterke voorkeur voor sociale vormen lijkend op gezichten boven niet-sociale vormen en voor menselijke beweging boven willekeurige beweging [1,2]. In de jaren hierop volgend ontwikkelen tal van vaardigheden die ons in staat stellen succesvol om te gaan met andere mensen. Veel van deze vaardigheden gebruiken we onbewust en zonder nadenken, maar toch vereisen ze enorme denkkracht om te navigeren door onze zeer sociale omgevingen [3]. Een zeer groot deel van het menselijk brein is dan ook betrokken bij de verwerking van sociale interacties en het begrijpen van andere mensen.

Voor lange tijd werden de hersenen grotendeels ingedeeld in cognitieve (ook wel "rationele") en affectief-gedreven (ook wel "emotionele") delen, die beide bijdragen aan het maken van complexe keuzes. Ongeveer 15 jaar geleden echter, merkten Frith \& Frith [4] op dat er ook een ander netwerk in de hersenen te ontdekken is, waar zij naar refereerden als het "sociale brein" netwerk. Dit netwerk is specifiek actief 
wanneer mensen nadenken over gedachten, intenties en handelingen van andere mensen. Het sociale brein netwerk bestaat uit verschillende samenwerkende hersenstructuren, zoals de mediale frontale cortex, de temporaal-pariëtale junctie, de superieure temporale sulcus, en de anterieure temporale kwab (zie Figuur 1 voor een overzicht). Interessant aan deze hersengebieden is, dat zij op de intersectie liggen van verschillende kwabben in de hersenen (zoals de temporaal-pariëtale junctie), dat zij een relatief lang ontwikkelingsverloop hebben in termen van grijze stof ontwikkeling (tot aan de begin twintiger jaren) [5], en dat onderdelen van het sociale brein netwerk groter zijn bij mensen dan bij andere dieren (zoals de mediale frontale cortex) [6].

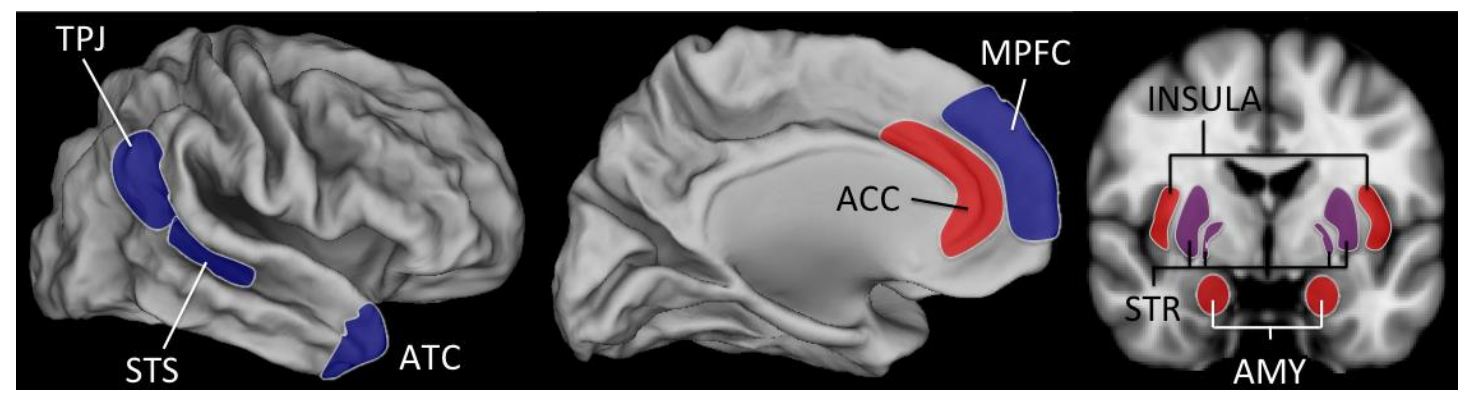

Figuur 1. Overzicht van verschillende hersengebieden betrokken bij de besproken sociale brein netwerken. TPJ = temporaal-pariëtale junctie; STS = superieure temporale sulcus; $\mathrm{ATC}=$ anterieure temporale cortex $\mathrm{ACC}=$ anterieure cingulate cortex MPFC = mediale prefrontale cortex $; \mathrm{STR}=$ striatum; $\mathrm{AMY}=$ amygdala

Recentelijk hebben onderzoekers benadrukt dat het sociale brein netwerk in meer detail te onderscheiden is met betrekking tot betrokkenheid bij verschillende psychologische processen. Voor een helder overzicht van het sociale brein is het daarom belangrijk om verschillende niveaus van wat 'sociaal' is te onderscheiden en het sociale brein op te delen in netwerken van samenwerkende hersengebieden in plaats van afzonderlijk functionerende structuren. In navolging van Kennedy en Adolphs [7] onderscheiden wij de volgende niveaus van beschrijving: het sociale brein zorgt voor de uitvoer van sociale denkprocessen (cognities), wat vervolgens leidt tot sociaal gedrag, en over langere tijd bepaalt dit iemands sociale functioneren in een bredere gemeenschap. Dankzij vele recente studies kunnen we de onderdelen van het sociale brein relateren aan verschillende processen, maar geen van deze sociale processen kan een-op-een worden gelinkt aan een enkele hersenstructuur. 
Daarom is het zinvoller een netwerkbenadering te gebruiken, wat betekent dat psychologische processen worden gelinkt aan netwerken van samenwerkende hersengebieden.

In dit artikel bespreken we de ontwikkeling van het sociale brein aan de hand van drie sociale brein netwerken die in eerder onderzoek onderscheidbaar waren: 1) een "perspectief-nemen" netwerk betrokken bij het nadenken over andermans gedachten, 2) een emotie-netwerk betrokken bij sociale acceptatie en afwijzing, en 3) een empathie netwerk betrokken bij het delen van andermans emoties [7]. We beschrijven vervolgens hoe deze netwerken ontwikkelen in kinderen en adolescenten. Aangezien de meeste ontwikkelingsstudies met behulp van beeldvormende technieken zijn uitgevoerd onder adolescenten richten we ons met name op de ontwikkeling van het sociale brein tijdens deze periode. De adolescentie is bovendien een vormende fase voor sociale ontwikkeling waarbij jongeren, gedeeltelijk afhankelijk van hun omgeving, zich ontwikkelen tot sociaal-betrokken volwassenen. We bespreken daarom ook wat bekend is over de ontwikkeling van deze netwerken bij jongeren die antisociaal gedrag vertonen, een groep die deels gekenmerkt wordt door afwijkend sociaal functioneren en het benadelen van anderen.

\section{De ontwikkeling van perspectief-nemen}

Veel van ons sociale gedrag is gericht op het begrijpen van intenties en perspectieven van anderen. Dit cognitief gedreven proces staat ook wel bekend als perspectiefnemen of theory of mind. Jonge kinderen leren vanaf ongeveer het derde en vierde levensjaar om perspectieven van anderen in te nemen, maar de vaardigheid tot perspectief-nemen ontwikkelt nog door tot in de adolescentie [8].

Onderzoekers hebben ontdekt dat de mediale prefrontale cortex en de temporaalpariëtale junctie samen een belangrijke rol hebben bij perspectief-nemen. Deze gebieden worden bijvoorbeeld actief als mensen zich inleven in een verhaal over andere mensen [9], wanneer zij in gedachten behaalde handelingen uitvoeren [8], of wanneer zij intenties van gezichten aflezen [10]. De mediale prefrontale cortex blijkt bij adolescenten zelfs sterker actief tijdens perspectief-nemen dan bij volwassenen [11]. Onderzoekers hebben dat geïnterpreteerd als automatischer en selectiever perspectief-nemen bij volwassenen [8]. De temporaal-pariëtale junctie, daarentegen, 
wordt juist sterker actief wanneer adolescenten opgroeien [12]. Dit gebied wordt vaker geassocieerd met het makkelijk kunnen switchen tussen verschillende perspectieven van anderen [13]. Ook wordt de temporaal-pariëtale junctie sterke actief als mensen spontaan het perspectief van anderen innemen [14].

Samengevat, activiteit in de mediale prefrontale cortex neemt af als adolescenten opgroeien en activiteit in de temporaal-pariëtale junctie neem toe. Uit een metaanalyse van 35 studies bleek dat deze gebieden ook gevoelig zijn voor cultuur, dat wil zeggen, zij hebben een ander activatie-patroon voor mensen die in westerse of Aziatische culturen zijn opgegroeid [15]. Dit kan betekenen dat de ontwikkeling van deze gebieden gevoelig is voor omgeving en mogelijk ook getraind kan worden.

Jongeren die antisociaal gedrag vertonen, en antisociale jongeren met hoge killeemotieloze trekken (gekenmerkt door verminderde schuld en empathie en ongevoeligheid voor andermans emoties), bezitten over het algemeen de vaardigheid om andermans perspectief te nemen. Zo vertonen zij bijvoorbeeld vergelijkbare activatie in de mediale prefrontale cortex tijdens perspectief-nemen als leeftijdsgenoten die geen antisociaal gedrag vertonen [16]. Onderzoek met behulp van meer interactieve beslissingsspellen laat wel afwijkende activiteit zien in de temporaal-pariëtale junctie bij antisociale jongeren [17,18]. Deze onderzoeken suggereren dat deze jongeren wel de vaardigheid bezitten om andermans perspectief te nemen (en dit bijvoorbeeld ook kunnen inzetten om anderen te manipuleren), maar dat zij niet in alle situaties geneigd zijn dit even makkelijk en automatisch te doen.

\section{De ontwikkeling van acceptatie en afwijzing}

Naast het cognitief gerichte netwerk wat we hierboven bespraken, is een ander gedeelte van het sociale brein netwerk juist meer afgestemd om te reageren op sociale inclusie. Hierbij hebben onderzoekers zich gericht op handelingen die het gevolg zijn van een sociale interactie zoals acceptatie of afwijzing. Acceptatie is heel belangrijk voor mensen; bij een groep horen wordt ook wel beschreven als een fundamentele behoefte van mensen [6]. Het proces van acceptatie is vaak onderzocht via een 'sociale media' format, waarbij deelnemers te zien krijgen of andere deelnemers hun foto of hun profiel wel (acceptatie) of niet (afwijzing) leuk vonden. Bij zowel acceptatie als afwijzing, in vergelijking met een neutrale controle conditie, wordt het 
netwerk in de hersenen actief wat bestaat uit de insula en de anterieure cingulate cortex (ACC) [19]. Dit netwerk wordt sterk actief als er iets gebeurt wat voor mensen saillant is. Vergelijkende ontwikkelingsstudies hebben aangetoond dat jongeren het ACC-insula netwerk net zo sterk activeren als volwassenen [20], wat mogelijk aantoont dat vanaf jonge leeftijd het verwerken van belangrijke saillante sociale informatie al aanwezig is [19].

Daarnaast blijkt dat er ook hersennetwerken actief worden specifiek voor acceptatie, met name het ventraal striatum en de amygdala [21]. Het ventraal striatum heeft een interessant ontwikkelingspatroon, want het is sterker actief bij adolescenten dan bij kinderen als er geld kan worden gewonnen in een gokspel [22]. Het wordt daarom ook wel omschreven als het beloningsgebied in de hersenen [23]. Ook bij sociale acceptatie is het sterker actief bij oudere adolescenten in vergelijking met jonge adolescenten en kinderen [24]. Dezelfde analyses voor afwijzing zijn minder eenduidig. Om het effect van afwijzing te bestuderen hebben onderzoekers gebruik gemaakt van een Cyberball spel, waarbij de deelnemer wordt buitengesloten van een balspel. Deze buitensluiting heeft een sterk effect op ervaren van zelf-controle en zelfwaarde, en er zijn aanwijzingen dat dit negatieve gevoel sterker is voor adolescenten [25]. Maar op hersenniveau wordt de adolescentieperiode vooral gekenmerkt door persoonlijke verschillen tussen jongeren. Dat wil zeggen, de ervaring van buitensluiting in de hersenen is sterk en saillant en gaat gepaard met activiteit in het insula-ACC netwerk. Maar deze activiteit is uitvergroot bij jongeren die een geschiedenis hebben van buitensluiting op school [26] en is minder uitgesproken bij jongeren die veel vrienden hebben [27].

Samengevat, acceptatie en afwijzing zijn belangrijke ervaringen die leiden tot een sterk en robuust netwerk van activiteit in het affectieve insula-ACC netwerk (betrokken bij afwijzing) en het emotionele subcorticale netwerk waar het ventraal striatum en de amygdala onderdeel van uitmaken (betrokken bij acceptatie). Voor acceptatie zijn er aanwijzingen dat het ventraal striatum hier sterker op reageert in volwassenen. Het afwijzingsnetwerk daarentegen is sterk gevoelig voor sociale ervaringen, zoals het wel of niet hebben van vriendschappen. Tot nu toe is hersenactivatie tijdens acceptatie en afwijzing weinig onderzocht in jongeren die antisociaal gedrag vertonen. Het zou interessant zijn om juist bij jongeren die 
bijvoorbeeld veel pesten dit verder te onderzoeken. Wel is het insula-ACC netwerk bij jongeren met hoge kille-emotieloze trekken veel onderzocht in de context van empathie, het onderwerp van de volgende paragraaf.

\section{De ontwikkeling van empathie}

Een ander meer affectief gericht netwerk binnen het sociale brein is een netwerk betrokken bij empathie, oftewel het delen van andermans emoties door iets soortgelijks te voelen als die ander voelt of verwacht wordt te voelen in een bepaalde situatie [28]. Dit is veelal onderzocht met behulp van reacties op emotionele stimuli zoals emotionele gezichten of pijn bij anderen. Met name bij empathie voor pijn studies blijken de hersengebieden die betrokken zijn bij het zelf ervaren van pijn zoals de insula, cingulate cortex, supplementaire motorische schors en amygdala, ook geactiveerd te worden wanneer pijn bij een ander gezien wordt [29]. De ontwikkeling van de hersennetwerken van pijn empathie is relatief weinig onderzocht, en een paar studies suggereren een verandering in amygdala activiteit die licht afneemt met leeftijd (tussen 7 en 40 jaar) in reactie op plaatjes van mensen in pijnlijke situaties [30,31]. Het lijkt erop dat dit meer basale deel van het sociale brein netwerk vroeger uitgerijpt is en niet meer sterk verder ontwikkelt in de adolescentie.

Tot voor kort werden beeldvormende technieken niet veel gebruikt bij kinderen onder de acht jaar, maar een recente studie heeft met behulp van een animatiefilm het empathie netwerk onderzocht in een groep van 122 kinderen van 3 tot 12 jaar oud [32]. Hierbij werd de korte Pixar film 'Partly Cloudy' in de scanner aan de kinderen getoond en werd de activiteit gemeten in het empathie netwerk tijdens scenes waarin de hoofdpersonen pijn ondergaan (bijv. worden gebeten door een krokodil of geëlektrocuteerd door een sidderaal) en in het perspectief-nemen netwerk tijdens scenes waarin de gedachten van de hoofdpersonen afgelezen kunnen worden (bijv. als de hoofdpersoon denkt dat hij wordt verlaten door een vriend of als een huilende baby weer blij wordt gemaakt). De resultaten van deze studie lieten zien dat het perspectief-nemen en empathie netwerk deels al te onderscheiden zijn op 3-jarige leeftijd en dat beide netwerken steeds beter te onderscheiden en dus sterker gespecialiseerd raken als kinderen ouder worden [32]. Deze elegante aanpak maakt het dus mogelijk om op een voor kinderen aantrekkelijke manier de ontwikkeling van 
verschillende netwerken binnen het sociale brein in hele jonge kinderen in kaart te brengen.

Samengevat, het empathie netwerk lijkt grotendeels in de kindertijd en voor de adolescentie te ontwikkelen. Er zijn aanwijzingen dat activiteit in de amygdala in reactie op andermans pijn toeneemt in de adolescentie, maar tijdens de adolescentie spelen onderlinge verschillen tussen jongeren waarschijnlijk een sterkere rol dan leeftijdseffecten. Juist het empathie netwerk is dan ook relatief veel onderzocht in antisociale jongeren met kille-emotieloze trekken. De belangrijkste kenmerken van kille-emotieloze trekken zijn dan ook verminderde empathie en ongevoeligheid voor andermans emoties, wat het voor onderzoekers interessant maakt om de neurale mechanismen die hieraan ten grondslag liggen te onderzoeken. Uit empathie voor pijn studies en reacties op emotionele gezichten (met name bij emoties zoals angst) blijkt inderdaad dat antisociale jongeren met kille-emotieloze trekken verminderde amygdala en insula activiteit vertonen vergeleken met leeftijdsgenoten die geen antisociaal gedrag vertonen $[33,34]$ en ook in vergelijking met jongeren met autisme [35]. Volgens een belangrijke theorie is het ervaren van andermans emoties essentieel voor morele ontwikkeling, omdat kinderen hierdoor leren dat het benadelen van anderen zorgt voor leed bij de ander [36]. De verminderde activiteit in het empathie netwerk duidt erop dat antisociale jongeren met kille-emotieloze trekken andermans emoties minder goed ervaren en daardoor sneller leed veroorzaken bij anderen.

\section{Conclusie}

Verschillende studies onder kinderen, jongeren en volwassenen tonen aan dat het sociale brein is op te delen in verschillende hersennetwerken, die zich bovendien op verschillend tempo ontwikkelen. De hersengebieden betrokken bij acceptatie en afwijzing en het ervaren van empathie zijn gevoelig voor onderlinge verschillen en omgevingsinvloeden, en lijken grotendeels uitgerijpt voor de adolescentie. Vooral het netwerk voor perspectief-nemen ontwikkelt nog gedurende de adolescentie. Ook lijken de verschillende sociale brein netwerken zich anders te ontwikkelen bij jongeren die antisociaal gedrag vertonen; met name het empathie netwerk functioneert anders en perspectief-nemen lijkt minder automatisch te gebeuren. Toekomstig onderzoek moet uitwijzen wat de invloed van de omgeving is op hersenontwikkeling bij jongeren die antisociaal gedrag vertonen. Een recente studie 
laat bijvoorbeeld zien dat jongeren die verminderde activiteit in de amygdala en temporaal-pariëtale junctie vertonen tijdens het inleven in anderen, meer probleemgedrag vertonen dan jongeren met meer activiteit in deze gebieden, maar dit geldt alleen als zij vroeg in de adolescentie veel aan criminaliteit zijn blootgesteld [37]. Deze resultaten suggereren dat een wisselwerking tussen omgevingsinvloeden en biologische gevoeligheid bijdraagt aan antisociaal gedrag. Meer kennis hierover kan helpen bij het ontwikkelen en op het juiste moment inzetten van interventies. Longitudinale onderzoeken, waarin jongeren voor langere tijd gevolgd worden, zullen in de toekomst hierbij kunnen helpen om nog beter in kaart kunnen brengen hoe de verschillende sociale brein netwerken zich ontwikkelen en in welke mate dit wordt beïnvloed door omgevingsfactoren zoals bijvoorbeeld sociale ervaringen.

\section{Referenties}

1. Simion F, Regolin L, Bulf H. A predisposition for biological motion in the newborn baby. Proc. Natl. Acad. Sci. U. S. A. 2008; 105(2):809-13. doi:10.1073/pnas.0707021105.

2. Valenza E, Simion F, Cassia VM, Umiltà C. Face preference at birth. J. Exp. Psychol. Hum. Percept. Perform. 1996; 22(4):892-903. doi:10.1037/00961523.22.4.892.

3. Frith CD, Frith U. The neural basis of mentalizing. Neuron. 2006; 50(4):531-4. doi:10.1016/j.neuron.2006.05.001.

4. Frith U, Frith CD. Development and neurophysiology of mentalizing. Philos. Trans. R. Soc. B Biol. Sci. 2003; 358(1431):459-473. doi:10.1098/rstb.2002.1218.

5. Mills KL, Lalonde F, Clasen LS, Giedd JN, Blakemore S-J. Developmental changes in the structure of the social brain in late childhood and adolescence. Soc. Cogn. Affect. Neurosci. 2014; 9(1):123-131. doi:10.1093/scan/nss113.

6. Dunbar RIM. The Anatomy of Friendship. Trends Cogn. Sci. 2018; 22(1):32-51. doi:10.1016/j.tics.2017.10.004.

7. Kennedy DP, Adolphs R. The social brain in psychiatric and neurological disorders. Trends Cogn. Sci. 2012; 16(11):559-72. doi:10.1016/j.tics.2012.09.006.

8. Dumontheil I, Apperly IA, Blakemore SJ. Online usage of theory of mind continues to develop in late adolescence. Dev Sci. 2010; 13(2):331-8. doi:10.1111/j.1467-7687.2009.00888.x.

9. Blakemore SJ, den Ouden H, Choudhury S, Frith C. Adolescent development of the neural circuitry for thinking about intentions. Soc. Cogn. Affect. Neurosci. 2007; 2(2):130-9. doi:10.1093/scan/nsm009.

10. Gunther Moor B, Op de Macks ZA, Güroğlu B, Rombouts SARB, Van der Molen MW, Crone EA. Neurodevelopmental changes of reading the mind in the eyes. Soc. Cogn. Affect. Neurosci. 2012; 7(1):44-52. doi:10.1093/scan/nsr020.

11. Burnett S, Bird G, Moll J, Frith C, Blakemore SJ. Development during Adolescence of the Neural Processing of Social Emotion. J. Cogn. Neurosci. 2009; 21(9):1736-1750. doi:10.1162/jocn.2009.21121. 
12. Güroğlu B, van den Bos W, Rombouts SA, Crone EA. Unfair? It depends: neural correlates of fairness in social context. Soc. Cogn. Affect. Neurosci. 2010; 5(4):414-23. doi:10.1093/scan/nsq013.

13. Carter RM, Huettel SA. A nexus model of the temporal-parietal junction. Trends Cogn. Sci. 2013; 17(7):328-36. doi:10.1016/j.tics.2013.05.007.

14. Van Hoorn J, Van Dijk E, Guroglu B, Crone EA. Neural correlates of prosocial peer influence on public goods game donations during adolescence. Soc. Cogn. Affect. Neurosci. 2016; 11(6):923-33. doi:10.1093/scan/nsw013.

15. Han S, Ma Y. Cultural differences in human brain activity: A quantitative metaanalysis. NeuroImage. 2014; 99:293-300. doi:10.1016/j.neuroimage.2014.05.062.

16. O’Nions E, Sebastian CL, McCrory E, Chantiluke K, Happe F, Viding E. Neural bases of Theory of Mind in children with autism spectrum disorders and children with conduct problems and callous-unemotional traits. Dev Sci. 2014; 17(5):786-96. doi:10.1111/desc.12167.

17. Klapwijk ET, Lelieveld GJ, Aghajani M, Boon AE, van der Wee NJ, Popma A, et al. Fairness decisions in response to emotions: a functional MRI study among criminal justice-involved boys with conduct disorder. Soc. Cogn. Affect. Neurosci. 2016; 11(4):674-82. doi:10.1093/scan/nsv150.

18. van den Bos W, Vahl P, Güroğlu B, van Nunspeet F, Colins O, Markus M, et al. Neural correlates of social decision-making in severely antisocial adolescents. Soc. Cogn. Affect. Neurosci. 2014; 9(12):2059-66. doi:10.1093/scan/nsu003.

19. Achterberg M, van Duijvenvoorde ACK, Bakermans-Kranenburg MJ, Crone EA. Control your anger! The neural basis of aggression regulation in response to negative social feedback. Soc. Cogn. Affect. Neurosci. 2016; 11(5):712-720. doi:10.1093/scan/nsv154.

20. Güroğlu B, van den Bos W, van Dijk E, Rombouts SA, Crone EA. Dissociable brain networks involved in development of fairness considerations: understanding intentionality behind unfairness. Neuroimage. 2011; 57(2):63441. doi:10.1016/j.neuroimage.2011.04.032.

21. Guyer AE, Choate VR, Pine DS, Nelson EE. Neural circuitry underlying affective response to peer feedback in adolescence. Soc. Cogn. Affect. Neurosci. 2012; 7(1):81-92. doi:10.1093/scan/nsr043.

22. Braams BR, van Duijvenvoorde AC, Peper JS, Crone EA. Longitudinal changes in adolescent risk-taking: a comprehensive study of neural responses to rewards, pubertal development, and risk-taking behavior. J. Neurosci. 2015; 35(18):722638. doi:10.1523/JNEUROSCI.4764-14.2015.

23. Delgado MR. Reward-Related Responses in the Human Striatum. Ann. N. Y. Acad. Sci. 2007; 1104(1):70-88. doi:10.1196/annals.1390.002.

24. Sherman LE, Greenfield PM, Hernandez LM, Dapretto M. Peer Influence Via Instagram: Effects on Brain and Behavior in Adolescence and Young Adulthood. Child Dev. 2018; 89(1):37-47. doi:10.1111/cdev.12838.

25. Sebastian C, Viding E, Williams KD, Blakemore S-J. Social brain development and the affective consequences of ostracism in adolescence. Brain Cogn. 2010; 72(1):134-145. doi:10.1016/j.bandc.2009.06.008.

26. Will G-J, van Lier PAC, Crone EA, Güroğlu B. Chronic Childhood Peer Rejection is Associated with Heightened Neural Responses to Social Exclusion During Adolescence. J. Abnorm. Child Psychol. 2016; 44(1):43-55. doi:10.1007/s10802-015-9983-0. 
27. Masten CL, Telzer EH, Fuligni AJ, Lieberman MD, Eisenberger NI. Time spent with friends in adolescence relates to less neural sensitivity to later peer rejection. Soc. Cogn. Affect. Neurosci. 2012; 7(1):106-114. doi:10.1093/scan/nsq098.

28. Decety J, Svetlova M. Putting together phylogenetic and ontogenetic perspectives on empathy. Dev. Cogn. Neurosci. 2012; 2(1):1-24. doi:10.1016/j.den.2011.05.003.

29. Lamm C, Decety J, Singer T. Meta-analytic evidence for common and distinct neural networks associated with directly experienced pain and empathy for pain. NeuroImage. 2011; 54(3):2492-2502. doi:10.1016/j.neuroimage.2010.10.014.

30. Decety J, Michalska KJ. Neurodevelopmental changes in the circuits underlying empathy and sympathy from childhood to adulthood. Dev. Sci. 2010; 13(6):88699. doi:10.1111/j.1467-7687.2009.00940.x.

31. Decety J, Michalska KJ, Kinzler KD. The Contribution of Emotion and Cognition to Moral Sensitivity: A Neurodevelopmental Study. Cereb. Cortex. 2011; 22(1):209-220. doi:10.1093/cercor/bhr111.

32. Richardson H, Lisandrelli G, Riobueno-Naylor A, Saxe R. Development of the social brain from age three to twelve years. Nat. Commun. 2018; 9(1):1027. doi:10.1038/s41467-018-03399-2.

33. Lockwood PL, Sebastian CL, McCrory EJ, Hyde ZH, Gu X, De Brito SA, et al. Association of callous traits with reduced neural response to others' pain in children with conduct problems. Curr. Biol. 2013; 23(10):901-5. doi:10.1016/j.cub.2013.04.018.

34. Sebastian CL, McCrory EJ, Dadds MR, Cecil CA, Lockwood PL, Hyde ZH, et al. Neural responses to fearful eyes in children with conduct problems and varying levels of callous-unemotional traits. Psychol. Med. 2014; 44(1):99-109. doi:10.1017/S0033291713000482.

35. Klapwijk ET, Aghajani M, Colins OF, Marijnissen GM, Popma A, van Lang $\mathrm{ND}$, et al. Different brain responses during empathy in autism spectrum disorders versus conduct disorder and callous-unemotional traits. J. Child Psychol. Psychiatry. 2016; 57(6):737-47. doi:10.1111/jcpp.12498.

36. Blair RJR. A cognitive developmental approach to morality: investigating the psychopath. Cognition. 1995; 57(1):1-29. doi:10.1016/0010-0277(95)00676-P.

37. Weissman DG, Gelardi KL, Conger RD, Robins RW, Hastings PD, Guyer AE. Adolescent Externalizing Problems: Contributions of Community Crime Exposure and Neural Function During Emotion Introspection in Mexican-Origin Youth. J. Res. Adolesc. 2018; 28(2):551-563. doi:10.1111/jora.12358. 